\title{
¿Equidad en la dotación de espacio público en Bogotá?
}

\section{Public Space endowment equity in Bogotá?}

\section{Julián Alberto Gutiérrez-López}

Universidad El Bosque, Bogotá (Colombia)

Grupo de investigación

Dinámicas Económicas y Administrativas

\section{Lina Fernanda Quenguan-López}

Departamento Administrativo de la Defensoría del Espacio Público, Bogotá (Colombia)

Grupo de investigación Análisis en Espacio Público

\section{Mario Andrés Betancourt-Carvajal}

Departamento Administrativo de la Defensoría del Espacio Público, Bogotá (Colombia)

Grupo de investigación Análisis en Espacio Público

Gutiérrez-López J. A Quenguan-López, LF \& Betancourt-Carvajal, M. A. (2020). iEquidad en la dotación de espacio público en Bogotá? Revista de Arquitectura (Bogotá), 22(I), 18-29. https://doi.org/10.14718/ RevArq.2020.2606

\section{Julián Alberto Gutiérrez-López}

Economista, Escuela Colombiana de Ingeniería Julio Garavito, Bogotá (Colombia) Magíster en ciencias económicas, Universidad Santo Tomás, Bogotá (Colombia).

(D) http://orcid.org/0000-000I-5296-0853 julkeled@hotmail.com

\section{Lina Fernanda Quenguan-López}

Geógrafa, Universidad Nacional de Colombia, Bogotá (Colombia).

Tecnóloga en gestión ambiental y servicios públicos.

Especialista en mercado y política de suelo en América Latina, Universidad Nacional de Colombia, Bogotá (Colombia).

Estudiante, Maestría en Ordenamiento Urbano Regional, Universidad Nacional de Colombia, Bogotá (Colombia).

(D) https://orcid.org/0000-000 I-8280-5782

Ifquenguanl@unal.edu.co

Mario Andrés Betancourt-Carvajal

Internacionalista, Colegio Mayor Nuestra Señora del Rosario, Bogotá (Colombia).

(D) https://orcid.org/0000-0002-|8|2-6803

mbetancourt@dadep.gov.co

\section{Resumen}

El acelerado crecimiento urbano genera mayor demanda en infraestructura de servicios y dotaciones. También ha modificado el espacio público de las ciudades, y en tal sentido, se espera que se distribuya de manera equitativa en la ciudad garantizando una óptima cobertura; en especial, para las poblaciones más vulnerables. El presente trabajo tiene como objetivo analizar la equidad en la distribución de espacio público en Bogotá, a partir de una caracterización, a escala localidad, de la pobreza (pobreza monetaria, pobreza extrema, índice de pobreza multidimensional, índice de calidad de vida y necesidades básicas insatisfechas). Adicionalmente, se analizan los indicadores de espacio público (espacio público efectivo, espacio público total y espacio público verde). Este análisis comparativo, a la luz de los conceptos de focalización, igualdad y progresividad, determina cuáles localidades presentan mayores niveles de pobreza en la ciudad, y si son las mismas que presentan mayores dotaciones en términos de inversión pública. Se establece un escenario de discusión frente a la implicación focalizada de las inversiones del gobierno local.

Palabras clave: calidad de vida; capital social; hábitat urbano; indicadores de pobreza; indicadores urbanos; política pública; segregación socioespacial; vulnerabilidad

\section{Abstract}

Accelerated urban growth generates greater demand of infraestructural services and endowments. It has also modified open, public space of cities, and in this regard, it is expected to be distributed in an equitable manner within the city, thus guaranteeing optimum coverage, especially for the most vulnerable populations. This work aims to analyze equity in the distribution of open public in Bogotá, based on a characterization of poverty, by districts, and its relationship with the quality indicators of public space. This analysis determines which locations have the highest levels of poverty in the city and if those are corresponding to the biggest allocation of amenities with the highest endowments, in terms of public investment. A discussion scenario is established in the face of the focused involvement of local government investments.

Keywords: quality of life; social capital; urban habitat; poverty indicators; urban indicators; public politics; socio-spatial segregation; vulnerability 


\section{Introducción}

El presente artículo es el resultado de la investigación ¿Equidad en la distribución del espacio público en Bogotá?, que adelantó el Observatorio de Espacio Púbico de Bogotá, y la cual tiene como objetivo determinar si existe equidad en la distribución del espacio público en la ciudad, teniendo como base el principio de focalización, desarrollado por el Departamento Nacional de Planeación (DNP).

El presente estudio se realiza con el fin de evidenciar si Bogotá presenta equidad en cuanto a la localización de sus espacios públicos, tomando como base el concepto de equidad desde los estudios realizados por Rawls (1971) sobre justicia e imparcialidad, partiendo, a su vez, de dos premisas de una sociedad justa: a) el principio de igual de derecho a un esquema de libertades básicas iguales (que requieren unos bienes sociales primarios básicos) y b) el principio de diferencia, el cual establece que las desigualdades económicas y sociales deben permitir la igualdad de oportunidades y el mayor beneficio de los miembros menos favorecidos de la sociedad (Rawls, 1971).

Con base en lo anterior, se puede decir que la equidad en la distribución de facilidades públicas debería conducir no a una igual provisión del servicio, pero sí, a un patrón de distribución que promueve la mayor igualdad de condiciones de acceso (Kirby, 1983). De esa forma, el presente estudio se concentra en la equidad espacial de la localización de espacios públicos, teniendo como premisa que las dotaciones deberán hacerse donde se concentra la mayor cantidad de población y donde se tengan los niveles de pobreza más altos en la ciudad.

Se toma como base el principio de focalización, que hace referencia a un conjunto de reglas o parámetros que permiten identificar a la población en condición de pobreza o con algún nivel de vulnerabilidad, como potenciales beneficiarios de inversiones públicas. Para este estudio se contrastan los indicadores de espacio público en la ciudad realizados por el Departamento Administrativo de la Defensoría del Espacio Público (DADEP, 2017) con los índices que normalmente son utilizados para desarrollar la focalización, a fin de verificar si la dotación de espacio público en la ciudad corresponde al desarrollo de este principio.

\section{La pobreza y el espacio público}

El crecimiento urbano, junto con las dinámicas del proceso de globalización, ha traído consigo cambios sustanciales en los espacios urbanos, debido a transformaciones sociales, culturales y económicas. La población urbana mundial pasó de 2300 millones de personas en 1994 a 3900 millones en 2014, según cifras de Naciones Unidas (2014); esto significa que a más población, deben aumentar los servicios y las dotaciones en la ciudad, para garantizar el bienestar de los ciudadanos; además, deben estar distribuidos de la mejor forma posible en el espacio urbano, para garantizar una óptima cobertura; en especial, la de la población más pobre. Según las Naciones Unidas (2016), hay más de 2200 millones de personas pobres en el mundo; en América Latina y el Caribe, cerca del $6 \%$ de la población vive en pobreza extrema.

Este escenario nos permite abrir diferentes interrogantes, tales como: ¿̇los espacios urbanos adoptan dentro de sus políticas territoriales acciones para minimizar las brechas entre ricos y pobres? Al ser un espacio que es de todos los ciudadanos, ¿qué papel juega el espacio público en el bienestar social? ¿El espacio público es un elemento que brinda equidad a los ciudadanos dentro de la ciudad? ¿Existe en la actualidad una mayor segmentación espacial dentro de las ciudades?

Para dar respuesta a los interrogantes planteados, es fundamental revisar el concepto de espacio público, al igual que su importancia para la ciudad y para el bienestar de los ciudadanos.

Existen varias visiones respecto a este concepto, y desde diferentes enfoques epistemológicos. Siguiendo a Carrión (2004), se encuentran cuatro formas de ver el espacio público: i) la concepción del urbanismo operacional, que lo simplifica a un remanente de las construcción privada, y cuya funcionalidad queda adscrita a la vinculación comercial y recreacional de los agentes; ii) la concepción jurídica, en la cual se entiende el espacio público como lo que no es privado, que es de todos y es adjudicado por el Estado; iii) la concepción filosófica radical, cuyo argumento al respecto es que el espacio público es donde confluyen los individuos a fin de satisfacer necesidades colectivas que van por encima de los intereses particulares, y iv) la concepción alternativa, que lo entiende históricamente como una parte inalienable de la ciudad y que muta en relación con ella.

Con estos enfoques, podemos decir que el espacio público es la ciudad. Siguiendo a Habermas (1993) y a Borja (2003), es el espacio donde se refleja o se materializa el poder y donde se concentra la ciudadanía. Es el espacio donde se ve reflejada gran parte de las políticas de la ciudad, mediante la conformación de las calles, los parques, las plazas y las zonas verdes. Es un espacio público entendido como un sistema, una red o un conjunto de elementos, de infraestructura, de equipamientos, de zonas comerciales que ordenan o configuran la ciudad plasmando en el espacio físico la expresión colectiva de los diferentes actores que intervienen la ciudad, y así se convierten en ese espacio principal del urbanismo (Borja \& Muxi, 2001).

El espacio público, de esta forma, se convierte en un indicador de calidad urbana y de política urbanística que califica los diferentes lugares de la ciudad, tanto centralidades como periferias, para dar paso a nuevos proyectos urbanos, para renovar o suturar espacios de la ciudad. 
Entendida dicha relación, es más sencillo imaginar cómo la dinámica urbana contribuye al aumento de las desigualdades sociales mediante la disminución del acceso real a las ofertas urbanas de la población más vulnerable, que queda marginada a las periferias, situación que levanta así muros reales o ficticios en la concepción de iguales como ciudadanos.

Este aislamiento influye en la calidad de vida de los individuos, debido al incremento en los costos de transporte, la disminución de las ofertas de bienes públicos y a la pérdida de identidad generada por el detrimento de la representación institucional, puesto que las "ciudades hoy son menos transitables, más inabarcables, más desconocidas, menos legibles $y$, por tanto, se han vuelto fuente de miedos y diferencias insuperables" (Segovia \& Jordán, 2005 , p. 7). Este aislamiento urbano, adicionalmente, imposibilita que los ciudadanos con menos ingresos puedan acceder a los beneficios de movilización de recursos diferentes de los que se movilizan en su entorno (Mayorga Henao \& García, 2018).

Este panorama, aunque desalentador, abre un reto significativo a la política pública desde distintos frentes, pero es labor de este trabajo abarcarla desde la óptica del espacio público, ya que este juega un papel fundamental en la concepción y en el desarrollo de la calidad de vida de forma general restableciendo identidad y generando cohesión entre los ciudadanos y su territorio.

En las ciudades donde la inversión en espacios públicos es limitada, se generan espacios públicos de baja calidad que se tornan vulnerables a aspectos como la inseguridad, lo cual genera en la ciudadanía una percepción de amenaza. Adicionalmente, los espacios públicos son los lugares donde se evidencian problemas de injusticia económica y social que generan una agorafobia urbana producida por la degradación o la desaparición de los espacios públicos integradores y protectores, a la vez que abiertos para todos (Borja \& Muxi, 2001).

Como lo resalta Davis (2001), citado por Segovia y Jordán (2005), esa percepción del espacio público genera

\section{(...) una reacción "natural" en respuesta a dicha amenaza —que eleva la cifra del temor y el miedo- es no salir, no exponerse, refugiarse en lugares privados: el auto bien cerrado, la casa bien enrejada, el barrio cerrado y vigilado, el suburbio bien alejado. (p. 10)}

Esta concepción desencadena, así mismo, un círculo vicioso entre el espacio público y su concepción, que pierde así su naturaleza articuladora, integradora y generadora de identidad colectiva.

Esta percepción del espacio público también hace que las actividades de esparcimiento, diversión, consumo y socialización sean relocalizadas

\begin{tabular}{|c|c|c|c|c|c|c|c|c|c|}
\hline Localidad & $\begin{array}{l}\text { Pobreza } \\
\text { monetaria }\end{array}$ & $\begin{array}{l}\text { Pobreza } \\
\text { extrema }\end{array}$ & $\begin{array}{c}\text { Incidencia, } \\
\text { pobreza } \\
\text { multidi- } \\
\text { mensional }\end{array}$ & $\begin{array}{c}\text { Intensidad, } \\
\text { pobreza } \\
\text { multidi- } \\
\text { mensional }\end{array}$ & ICV & $\begin{array}{c}\text { Personas } \\
\text { pobres } \\
\text { por NBI }\end{array}$ & $\begin{array}{c}\% \text { de } \\
\text { personas } \\
\text { pobres por } \\
\text { NBI }\end{array}$ & $\begin{array}{c}\text { Personas } \\
\text { en miseria } \\
\text { por NBI }\end{array}$ & $\begin{array}{c}\% \text { de } \\
\text { Personas } \\
\text { en miseria } \\
\text { por NBI }\end{array}$ \\
\hline
\end{tabular}

\begin{tabular}{|c|c|c|c|c|c|c|c|c|c|}
\hline Antonio Nariño & 9,5 & 2,4 & 8,8 & 39,6 & 91,8 & 2.845 & 2,6 & 216 & 0,2 \\
\hline Barrios Unidos & 10,2 & 3,7 & 6,4 & 40,6 & 95,0 & 6.127 & 2,5 & 0 & 0,0 \\
\hline Bosa & 23,5 & 5,2 & 18,2 & 40,1 & 89,2 & 37.636 & 6,0 & 0 & 0,0 \\
\hline Chapinero & 9,1 & 6,1 & 4,0 & 39,2 & 96,9 & 3.351 & 2,4 & 0 & 0,0 \\
\hline Ciudad Bolívar & 29,3 & 6,3 & 13,4 & 39,6 & 87,6 & 47.033 & 7,0 & 2.147 & 0,3 \\
\hline Engativá & 9,0 & 3,2 & 7,6 & 39,7 & 93,8 & 15.273 & 1,7 & 0 & 0,0 \\
\hline Fontibón & 9,1 & 3,4 & 8,3 & 38,9 & 93,2 & 10.842 & 2,9 & 415 & 0,1 \\
\hline Kennedy & 17,4 & 4,9 & 12,0 & 39,8 & 91,8 & 46.457 & 4,4 & 0 & 0,0 \\
\hline La Candelaria & 15,9 & 5,0 & 8,7 & 40,5 & 91,1 & 989 & 4,0 & 66 & 0,3 \\
\hline Los Mártires & 15,6 & 4,6 & 12,6 & 39,7 & 91,9 & 4.285 & 4,3 & 492 & 0,5 \\
\hline Puente Aranda & 12,5 & 5,8 & 8,2 & 41,2 & 93,6 & 6.475 & 2,5 & 508 & 0,2 \\
\hline Rafael Uribe & 17,8 & 3,5 & 16,4 & 41,6 & 90,0 & 26.805 & 7,0 & 3.562 & 0,9 \\
\hline San Cristóbal & 23,1 & 4,7 & 15,1 & 41,6 & 89,3 & 25.127 & 6,1 & 2.879 & 0,7 \\
\hline Santa Fe & 23,2 & 4,6 & 17,4 & 41,3 & 89,1 & 12.169 & 11,6 & 1.457 & 1,4 \\
\hline Suba & 8,1 & 2,3 & 9,5 & 39,3 & 93,2 & 32.610 & 2,8 & 0 & 0,0 \\
\hline Teusaquillo & 4,3 & 3,5 & 1,5 & 38,3 & 97,1 & 815 & 0,5 & 0 & 0,0 \\
\hline Tunjuelito & 15,0 & 2,3 & 10,5 & 39,5 & 90,7 & 7.750 & 3,8 & 625 & 0,3 \\
\hline Usaquén & 9,4 & 3,7 & 5,2 & 38,8 & 95,3 & 14.039 & 2,9 & 584 & 0,1 \\
\hline Usme & 29,1 & 5,3 & 19,1 & 39,0 & 88,3 & 28.217 & 6,7 & 2.360 & 0,6 \\
\hline
\end{tabular}

ICV: Índice de calidad de vida; NBI: necesidades básicas insatisfechas.

(A) Tabla 1. Indicadores de pobreza a escala de localidad.

Fuente: elaboración propia, con base en datos de la Secretaría Distrital de Planeación y la Encuesta Multipropósito 2017. 
en diferentes escenarios privados, como parques, centros comerciales y gimnasios, lo cual se debe a que dichos espacios reflejan seguridad, limpieza, tranquilidad y modernismo, frente a los espacios públicos que, ya se mencionó, son catalogados como inseguros, indeseados y peligrosos.

Esta concepción genera mayores inequidades sociales, ya que el goce y el disfrute de actividades que se podían realizar en bienes de uso público son privatizadas, o su utilización ya depende de un desembolso de dinero. Actividades como jugar, trotar o caminar ya se desarrollan en entornos privados, a los cuales solo tienen acceso las personas que por su condición económica y social pueden generar el correspondiente tipo de pagos, y ello genera un sesgo en el uso y la percepción del espacio público, ligado ahora a una función comercial.

Ante los escenarios descritos, el espacio público debe ser repensado, debe plantearse como una solución, y no como un problema; debe adecuarse a las nuevas concepciones de los individuos, se debe entender la tendencia a la individualización generada por la segregación espacial y a la comunalización generada por la inclusión en redes. En palabras de Castells (2003), citado por Segovia \& Jordán (2005): "somos cada día más conscientes de nuestra individualidad, pero al mismo tiempo creamos nuestras propias redes de relación que nos permiten seguir conectados y compartir intereses aunque estemos aislados socialmente" (p. 11).

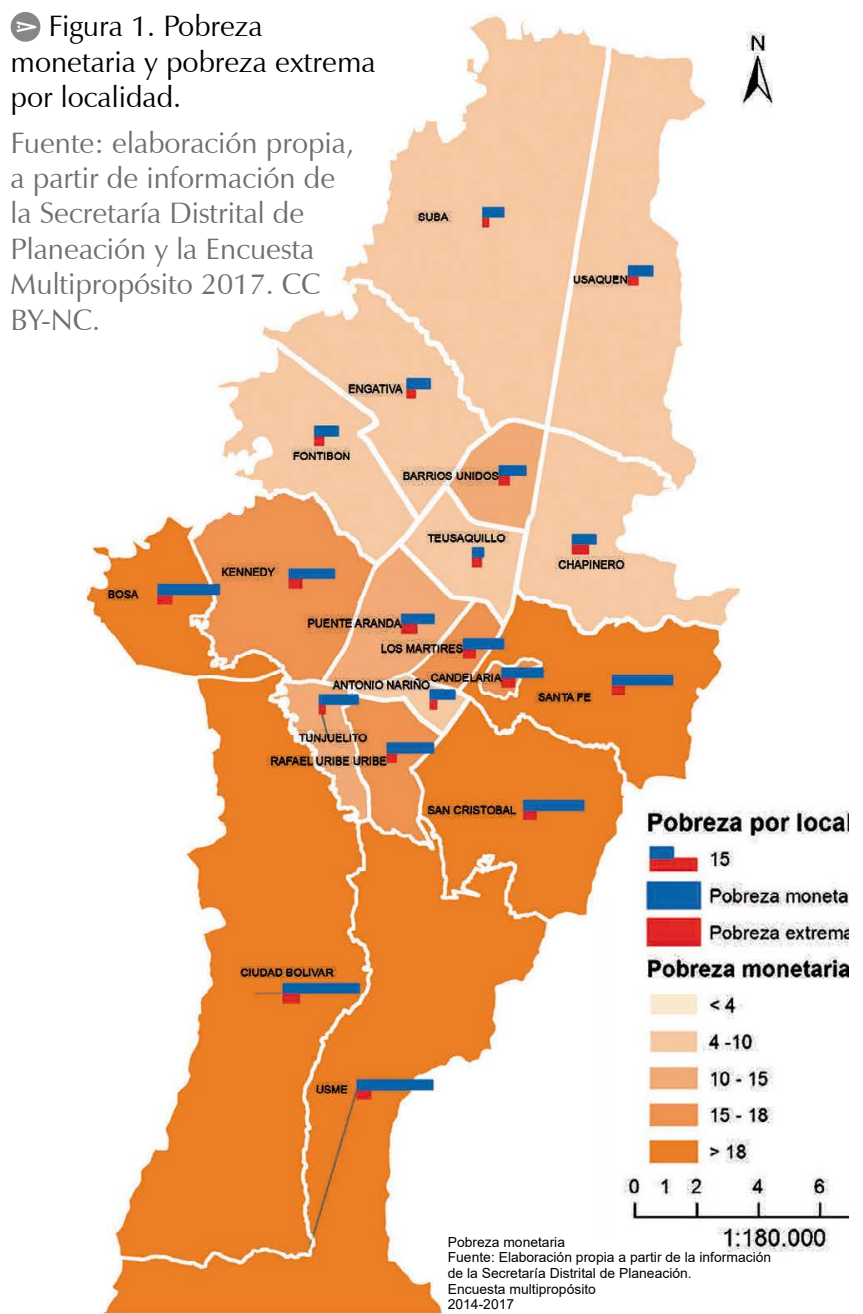

En suma, el espacio público debe convertirse en un generador de capital social en los planos individual y colectivo, ya que este se alimenta de círculos virtuosos donde las vivencias positivas reafirman la cooperación, dado que en dichos espacios se presentan eventos, experiencias y circunstancias que contribuyen a generar capital social mediante la creación o el refuerzo de los sentidos simbólicos de lo que es ser ciudadano, tales como jugar fútbol con los vecinos, asistir a un concierto en una plaza o, simplemente, tomarse un café al aire libre. El espacio público es un desafío y una oportunidad para la justicia urbana, desde el ámbito local hasta el ámbito global, donde se reflejan las necesidades y los gustos de los ciudadanos.

\section{Metodología}

Para verificar si Bogotá aplica de forma efectiva el principio de focalización para la dotación de espacio público en la ciudad, en primer momento se realizó un análisis de diferentes indicadores que dan cuenta de la pobreza y del nivel de calidad de vida de la ciudad en el ámbito de localidad (pobreza monetaria, pobreza extrema, índice de pobreza multidimensional, índice de calidad de vida y necesidades básicas insatisfechas) partiendo de la encuesta multipropósito ${ }^{1}$ realizada para

1 Dicha encuesta es elaborada conjuntamente por la Secretaría Distrital de Planeación (SDP) y el Departamento Administrativo Nacional de Estadística (DANE), y su objetivo principal es obtener información estadística sobre aspectos sociales, económicos y del entorno urbano de los hogares y habitantes de Bogotá (SDP, 2015; DANE, 2014).

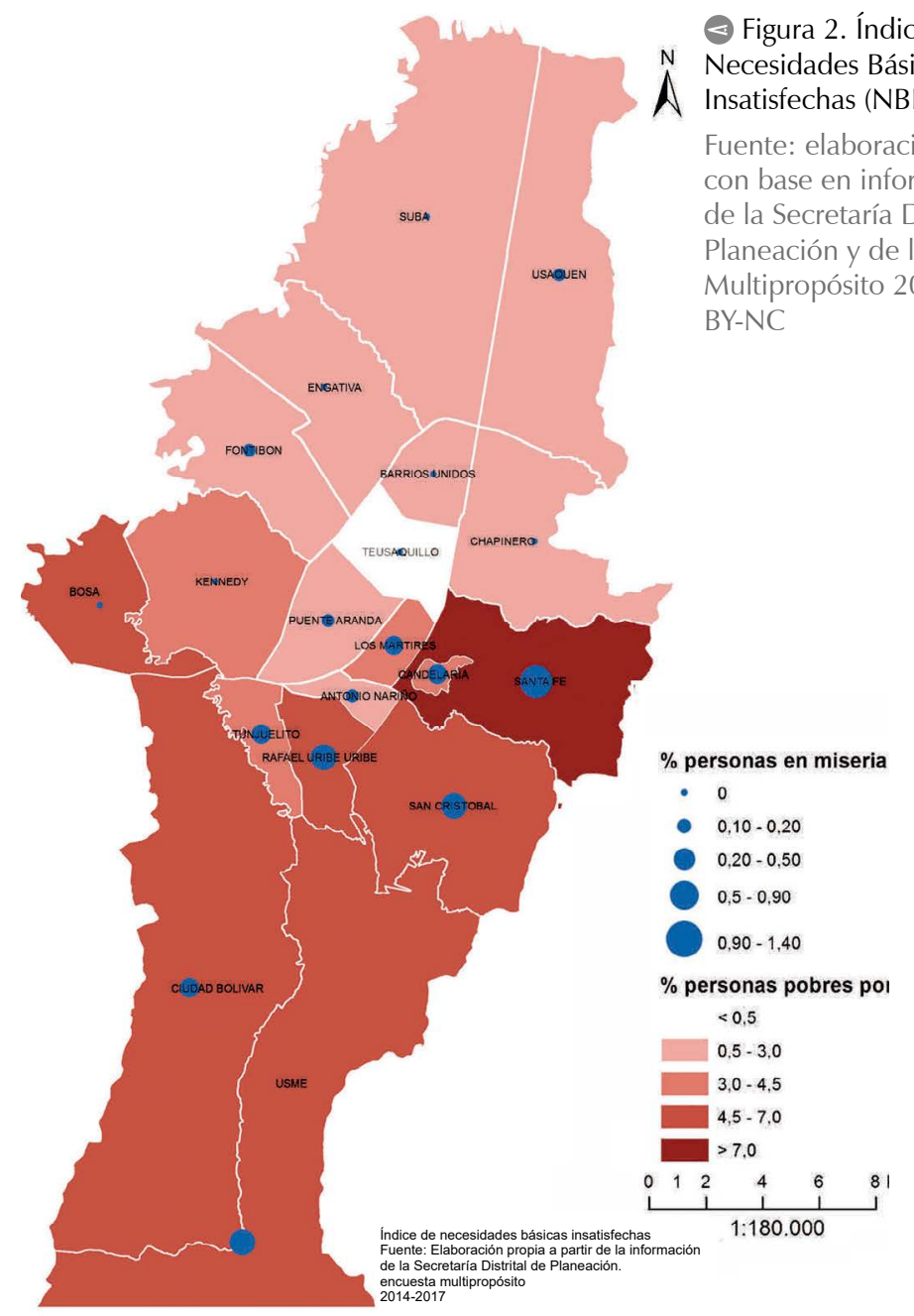


2014. En el segundo momento se analizan los indicadores base de espacio público para la ciudad de Bogotá, espacio público efectivo, espacio público total y espacio público verde a escala de localidad, hechos por el DADEP para 2017, con el fin de evidenciar qué localidades tienen una mejor dotación de espacio público en relación con sus habitantes. De esta forma, se hace un ordenamiento a escala de localidad de los diferentes indicadores, con el fin de identificar las localidades más pobres según cada una de las diferentes medidas de pobreza; de igual forma, se genera el ordenamiento en términos de dotación de espacio público, a fin de realizar análisis de orden comparativo.

Para evaluar de forma estadística los resultados obtenidos, se desarrollaron dos métodos que permiten dar cuenta de si se aplica el principio de focalización en la dotación de espacio público en la ciudad: se desarrolló el coeficiente de correlación, donde se analizó la relación lineal entre dos variables independientes, y se hicieron diagramas de distribución; específicamente, la Curva de Lorenz, la cual es utilizada con frecuencia para plasmar la distribución relativa de una variable en un dominio determinado. Para este caso, la variable dotación de espacio público de cada localidad, en relación con el porcentaje acumulado del espacio público de la ciudad. Igualmente, se calcula de forma numérica el coeficiente de Gini, el cual es un indicador de desigualdad que mide la concentración; en este caso, la del espacio público, donde 1 es una desigualdad perfecta en la dotación, y 0 , una igualdad perfecta en ella.

\section{Resultados}

\section{La pobreza en Bogotá a escala de localidad}

Para caracterizar la pobreza a escala de localidad, se utilizó la información de la Encuesta Multipropósito $2014^{2}$, con el grado de desagregación necesario. Para ello, se tomaron los datos por localidad de los siguientes indicadores: pobreza monetaria, pobreza extrema, índice de pobreza multidimensional, índice de calidad de vida y necesidades básicas insatisfechas. Se analizaron dichos indicadores entre sí para cada localidad, y por medio de mapas se evidenció la localización de los diferentes tipos de pobreza en la ciudad.

Los resultados de la pobreza a escala de localidad, en términos de pobreza monetaria, índice de pobreza multidimensional, índice de calidad de vida y necesidades básicas insatisfechas se registran en la tabla 1 .

Es así como para la pobreza monetaria a escala de localidad, se encuentran diferencias significativas, (tabla1, figura 1): localidades como Ciudad Bolívar y Usme presentaron porcentajes del $29,3 \%$ y el $29,1 \%$, respectivamente; dicho porcentaje indica que de cada 10 habitantes de la localidad, aproximadamente 3 son pobres. Esta cifra representa casi 7 veces el porcentaje de la localidad de Teusaquillo, que cuenta solo con el $4,3 \%$ de pobreza monetaria, y más de 3 veces el porcentaje de Suba, que cuenta con el $8,1 \%$.

2 Dicha encuesta es la investigación más reciente en el tema para el momento de desarrollo de la presente investigación.

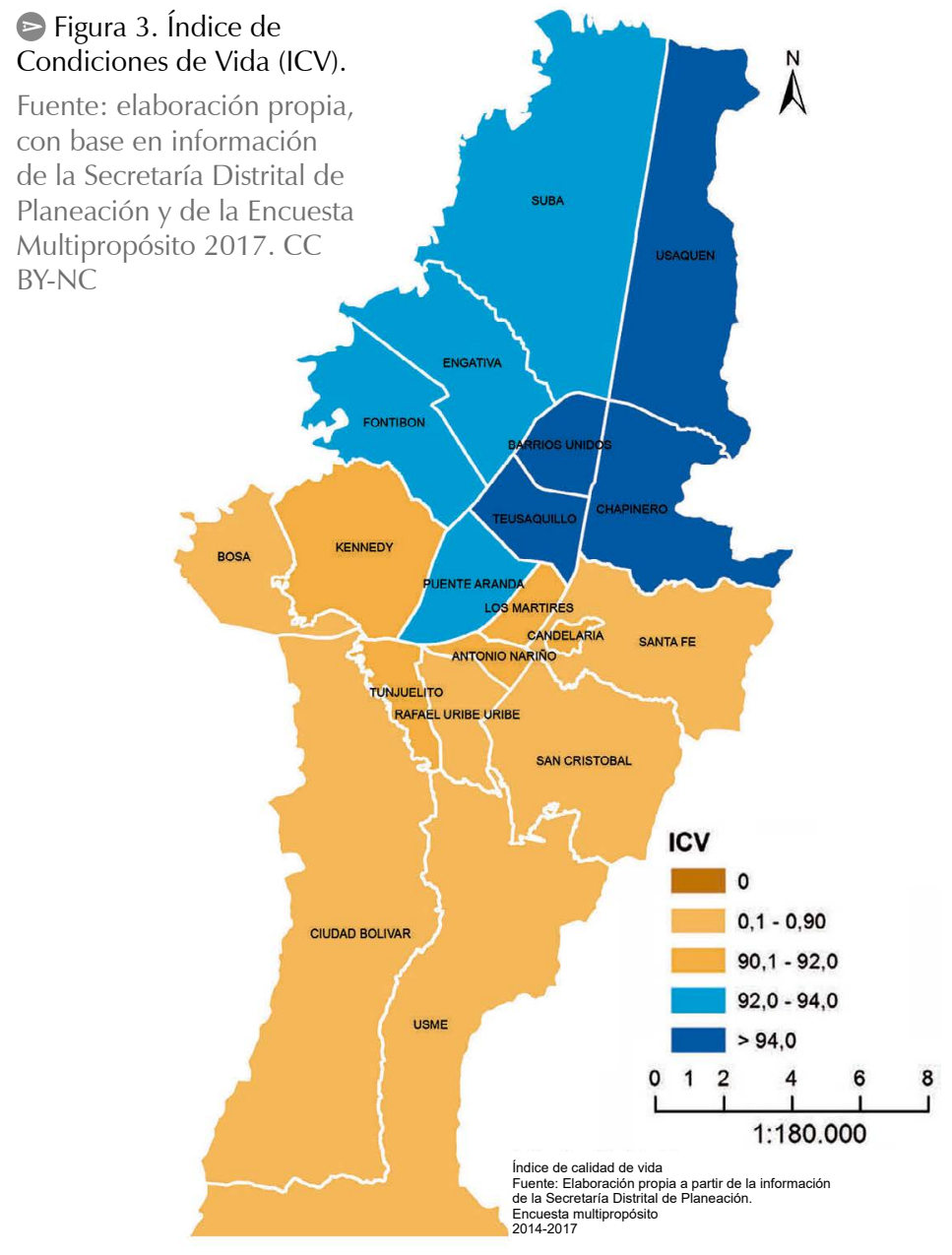

$>$ Figura 4. Índice de

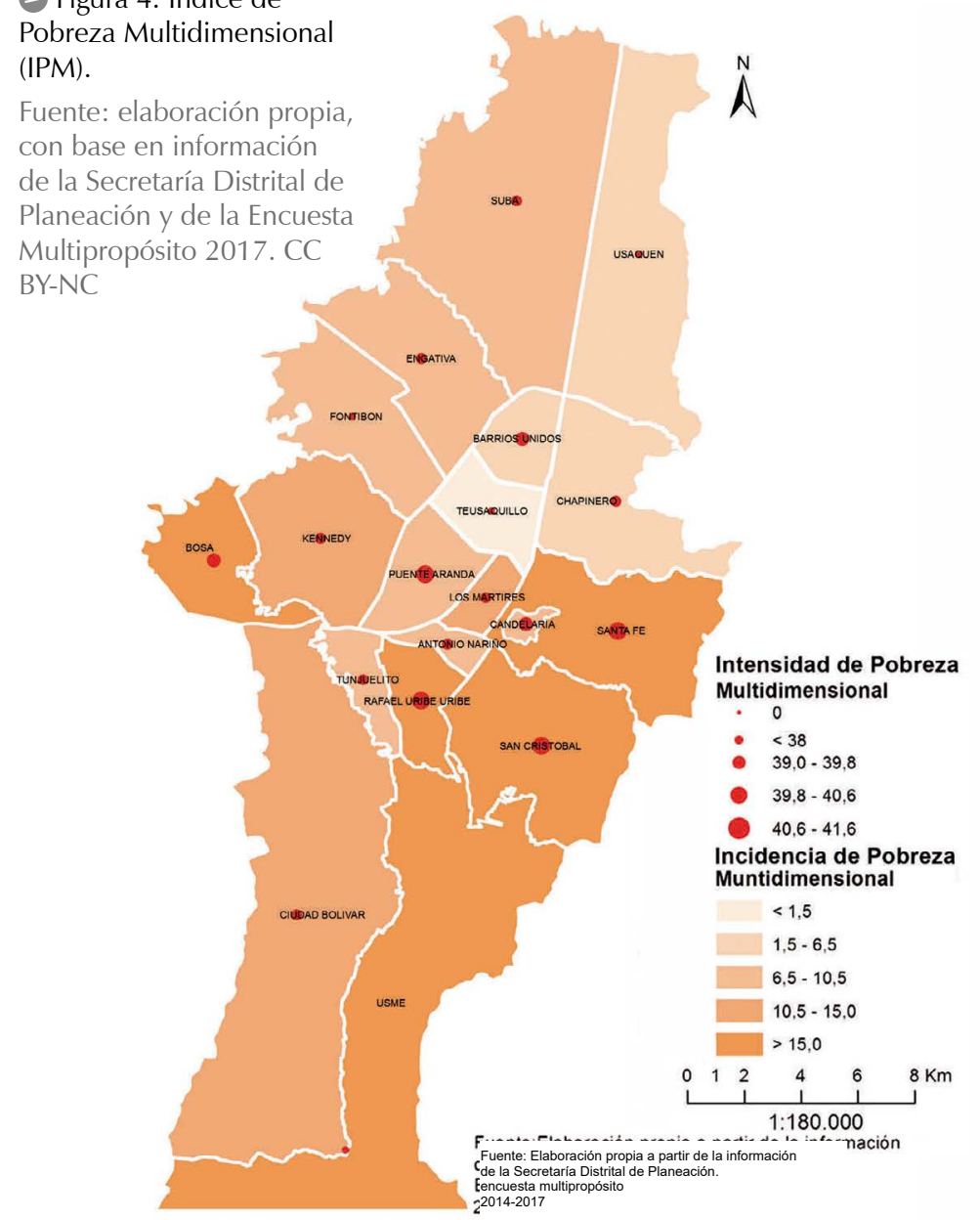


En cuanto al análisis de pobreza extrema, según la tabla 1 , se encontró que en la localidad de Teusaquillo, aunque esta presentaba el menor porcentaje de pobreza en general, dicha distinción no se da para el caso específico de la pobreza extrema, pues la localidad se encuentra en la sexta posición, con un porcentaje del $3,5 \%$. Las localidades con menor porcentaje de pobreza extrema son Suba y Tunjuelito, con el 2,3\% para ambos casos. Así mismo, las localidades con los porcentajes más altos fueron Ciudad Bolívar y Chapinero, con el 6,3\% y el 6,1\%, respectivamente; esto es, casi 3 veces las cifras de Suba y de Tunjuelito.

En cuanto al Índice de Necesidades Básicas Insatisfechas - NBI-, (tabla 1, figura 2) las brechas entre las localidades son más pronunciadas respecto a los porcentajes de pobreza monetaria. Las localidades con menor cantidad de personas pobres por $\mathrm{NBI}$ fueron Teusaquillo y Engativá, con porcentajes del $0,5 \%$ y el $1,7 \%$, respectivamente; en contraste, las localidades de Santa Fe y de Rafael Uribe presentan tasas del 1,6\% y el $7 \%$, respectivamente; o sea, 23 y 14 veces, respectivamente, el porcentaje de Teusaquillo.

Las condiciones de la localidad de Santa Fe se hacen más críticas si se analizan las cifras de las personas en condición de miseria por NBI, pues presenta un porcentaje del 1,4\%, lo cual es dos veces más que la antepenúltima localidad con peor indicador: San Cristóbal.

En relación con el Índice de Condiciones de Vida (ICV), (tabla 1, figura 3) desagregado por localidad, se pudo determinar que el promedio de las localidades es de 92 puntos. Aquellas con el peor índice fueron Ciudad Bolívar y Usme, con puntajes de 87,6 y 88,3, respectivamente (aproximadamente, 4 puntos porcentuales por debajo, en comparación con el promedio). Cabe agregar que, si bien el índice determina condiciones diferentes de los ingresos, dichas localidades también eran las que tenían los porcentajes más altos respecto al indicador de pobreza monetaria; así mismo, las localidades que se encontraron por debajo del promedio son: Santa Fe, Bosa, San Cristóbal, Rafael Uribe, Tunjuelito, La Candelaria, Antonio Nariño, Kennedy y Los Mártires.

Al comparar los resultados del ICV respecto a los resultados de la encuesta Multipropósito de 2011, se pudo evidenciar que las localidades de San Cristóbal, Usme, Tunjuelito, Bosa, Kennedy, Engativá, Suba, Barrios Unidos, Teusaquillo y Los Mártires incrementaron los puntajes de capital social básico, acumulación colectiva de bienes y acumulación individual de bienes materiales (Secretaría Distrital de Planeación [SDP], 2015, p. 200).

Por otra parte, el Índice de Pobreza Multidimensional (IPM), (figura 4), arrojó un promedio de las localidades del 10,67\%; aunque este índice es alto, la cifra cobró importancia al analizar detalladamente los datos, pues las dos localidades con los índices más bajos, Usme y Bosa, presentan un porcentaje doce veces más alto que la localidad de Teusaquillo.

Entre otras cosas, al analizar la intensidad de la pobreza, entendiendo esta como la cantidad
Tabla 2. Indicadores de espacio público por localidad. Fuente: elaboración propia, partir de los datos del Observatorio de Espacio Público. Reporte técnico de indicadores de espacio público. DADEP, 2017

\begin{tabular}{|c|c|c|c|c|c|c|}
\hline Localidad & $\begin{array}{c}\text { Área-EPE } \\
\mathbf{m}^{2}\end{array}$ & $\begin{array}{c}\text { Área-EPV } \\
\text { m }^{2}\end{array}$ & $\begin{array}{c}\text { Área-EPT } \\
\text { m }^{2}\end{array}$ & $\begin{array}{c}\text { EPE } \\
\mathrm{m}^{2} / \mathrm{hab}\end{array}$ & $\begin{array}{c}\text { EPV } \\
\text { m²/hab }^{2}\end{array}$ & $\begin{array}{c}\text { EPT } \\
\mathrm{m}^{2} / \mathrm{hab}\end{array}$ \\
\hline Usaquén & $2.523 .433,3$ & $5.963 .928,1$ & $13.221 .932,3$ & 5,3 & 12,6 & 28,0 \\
\hline Chapinero & $1.046 .387,4$ & $2.157 .345,7$ & $5.258 .412,6$ & 8,2 & 17,0 & 41,4 \\
\hline Santafé & $864.421,3$ & $1.091 .649,7$ & $2.795 .556,9$ & 9,0 & 11,3 & 29,0 \\
\hline San Cristóbal & $1.405 .600,4$ & $2.820 .628,6$ & $6.450 .768,3$ & 3,5 & 7,1 & 16,3 \\
\hline Usme & $2.113 .152,5$ & $12.684 .287,8$ & $16.080 .970,5$ & 6,3 & 37,6 & 47,7 \\
\hline Tunjuelito & $960.097,1$ & $2.836 .099,0$ & $4.783 .946,0$ & 5,1 & 15,0 & 25,2 \\
\hline Bosa & $1.522 .802,6$ & $6.108 .424,0$ & $10.514 .736,1$ & 2,1 & 8,6 & 14,8 \\
\hline Kennedy & $3.664 .817,7$ & $6.925 .001,9$ & $16.437 .610,8$ & 3,1 & 5,8 & 13,8 \\
\hline Fontibón & $1.813 .564,4$ & $5.124 .213,5$ & $10.689 .907,5$ & 4,5 & 12,7 & 26,5 \\
\hline Engativá & $4.945 .277,5$ & $9.393 .411,0$ & $17.618 .825,9$ & 5,7 & 10,8 & 20,2 \\
\hline Suba & $5.117 .915,6$ & $10.630 .187,6$ & $21.348 .185,6$ & 4,1 & 8,5 & 17,1 \\
\hline Barrios Unidos & $1.745 .436,3$ & $2.083 .587,7$ & $5.730 .984,7$ & 6,6 & 7,9 & 21,7 \\
\hline Teusaquillo & $1.805 .182,9$ & $2.112 .215,2$ & $6.298 .920,4$ & 12,8 & 15,0 & 44,7 \\
\hline Los Mártires & $190.908,4$ & $203.174,5$ & $2.382 .597,4$ & 2,0 & 2,2 & 25,3 \\
\hline Antonio Nariño & $310.454,0$ & $471.109,8$ & $2.009 .530,9$ & 2,8 & 4,3 & 18,4 \\
\hline Puente Aranda & $1.213 .925,9$ & $1.592 .456,7$ & $7.094 .387,8$ & 5,4 & 7,1 & 31,5 \\
\hline La Candelaria & $68.373,1$ & $103.709,1$ & $569.659,4$ & 3,0 & 4,6 & 25,2 \\
\hline Rafael Uribe & $1.147 .944,6$ & $1.529 .530,6$ & $4.874 .963,3$ & 3,2 & 4,3 & 13,8 \\
\hline Ciudad Bolívar & $2.284 .928,6$ & $6.642 .789,9$ & $11.948 .089,5$ & 3,2 & 9,2 & 16,6 \\
\hline
\end{tabular}



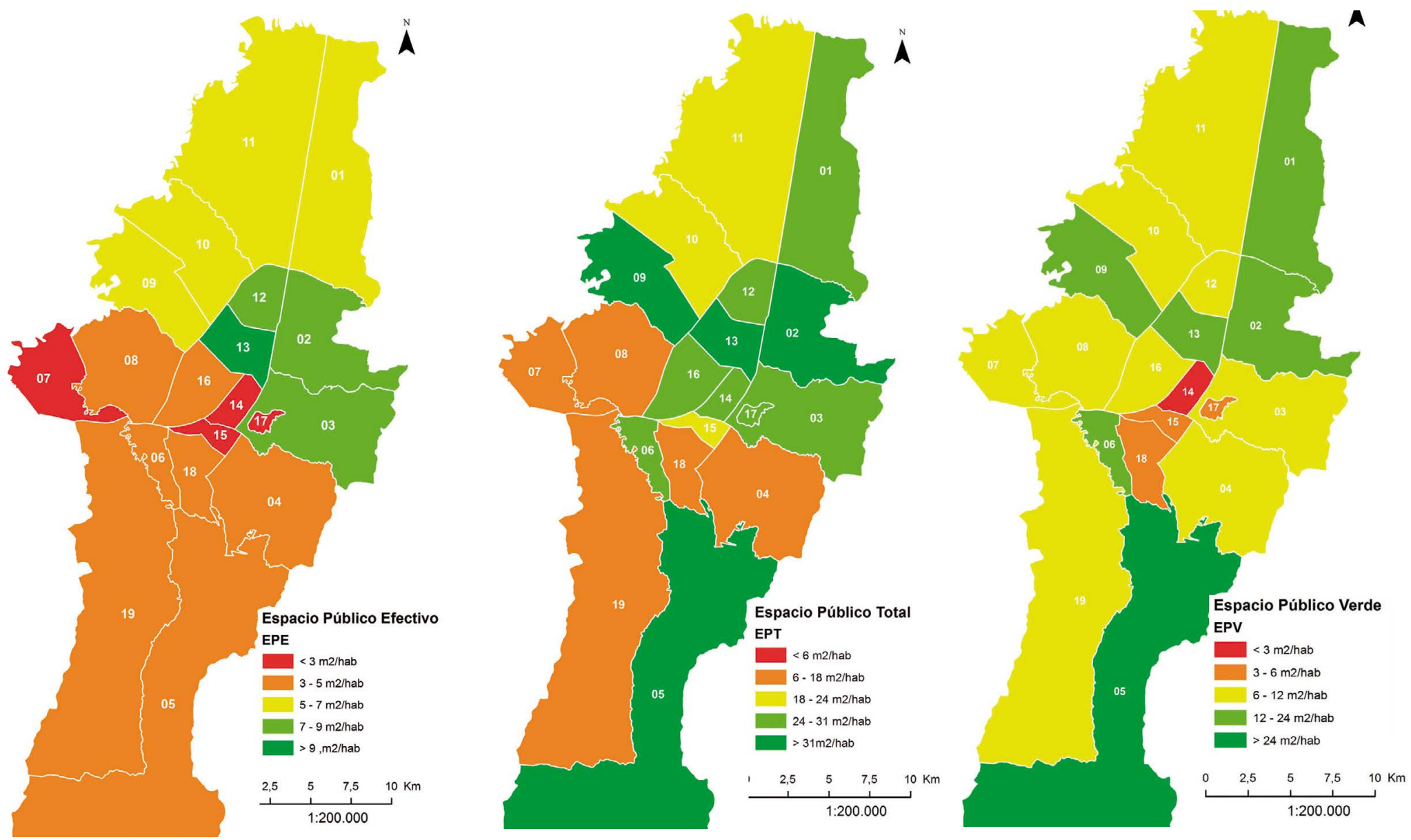

(A) Figura 5. Indicadores de espacio público por localidad.

Fuente: elaboración propia, con base en datos del

Observatorio del Espacio

Público de Bogotá. Reporte técnico de indicadores de espacio público (2017). CC BY-NC promedio de carencias simultáneas que sufren las personas pobres (Morales, 2000), se encontró que dentro de las localidades, incluyendo las de menor incidencia, la intensidad es preocupante, pues la localidad de Teusaquillo mostró un puntaje de 38,3 frente a Usme, con 39, lo cual indica que las políticas de disminución de la pobreza deberían estar redistribuidas para toda la ciudad, en las diferentes escalas.

\section{La inequidad en la distribución del espacio público}

Para analizar la distribución del espacio público a la luz del proceso de la focalización, entendiendo este como el "proceso mediante el cual se garantiza que el gasto social se asigne a los grupos de población más pobre y vulnerable" (Ley 715, 2001, art. 94; Ley 1176, 2007 art. 24), es fundamental analizar si la distribución del espacio público tiene en cuenta en su proceso de planificación dicho instrumento. Para ello, el punto de partida fue la distribución del espacio público en las localidades de la ciudad, por lo que se hizo el análisis de los indicadores base de espacio público a escala de localidad, realizados por el DADEP (2017).

El primer indicador base fue el de espacio público efectivo (EPE), y se lo define por:

$E P E=\frac{A_{p}+A_{p p}+A_{z v}}{\text { habitantes }}\left(\frac{m^{2}}{\text { habitantes }}\right)$

Donde $A_{p}$ corresponde al área de parques; App, al área de plazas y plazoletas, y $A_{z v}$, al área de zonas verdes.
El indicador de espacio público verde (EPV) se define por:

$$
E P V=\frac{A_{p}+A_{z v}+A_{e e p}}{\text { habitantes }}\left(\frac{m^{2}}{\text { habitantes }}\right)
$$

Donde $A_{p}$ corresponde al área de parques; $A_{z v}$, al área de zonas verdes, y $A_{e e p}$, al área de los elementos que componen la estructura ecológica principal.

El indicador de espacio público total (EPT) se define por:

$$
E P T=\frac{A_{\theta p \theta}+A_{c v}+A_{\theta \theta p}}{\text { habitantes }}\left(\frac{m^{2}}{\text { habitantes }}\right)
$$

Donde $A_{e p e}$ corresponde al área de espacio

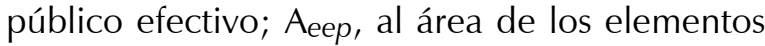
que componen la estructura ecológica principal, y $A_{C V}$, al área de los componentes viales (andén, calzada, ciclorruta, separador, control ambiental y vías peatonales).

Determinadas las condiciones de cálculo de cada indicador, se presentaron los resultados a escala de localidad:

Al revisar los resultados de los indicadores de espacio público (EPE, EPV, EPT), se encontró que las localidades con menor disponibilidad de espacio público efectivo (que hace alusión a plazas, plazoletas y parques) por habitante son Bosa, Los Mártires y Antonio Nariño. Adicionalmente, de forma visual, como lo constatan los mapas de indicadores de espacio público, (figura 5, tabla 2 ), la zona sur cuenta con los peores indicadores 
frente a la zona nororiental, que presenta indicadores ostensiblemente mejores: se destaca la localidad de Teusaquillo como un hito dentro de las localidades, ya que en ella se encuentra localizado el Parque Metropolitano Simón Bolívar. Frente al indicador de espacio público verde, se encontró que la ciudad, en general, presenta un déficit; se destacan la localidad de Los Mártires, por presentar el indicador más bajo $\left(2,2 \mathrm{~m}^{2} / \mathrm{hab}\right)$, y la localidad de Usme, por tener el indicador más alto $\left(37,6 \mathrm{~m}^{2} / \mathrm{hab}\right)$

\section{Pobreza vs. espacio público}

Al analizar las cifras mencionadas, junto con los mapas que describen las dotaciones del espacio público de la ciudad, y comparando todo ello con las cifras de pobreza, se encontraron datos interesantes en términos de desigualdad.

Al disponer las localidades en orden descendente frente al EPE, y donde 1 es la localidad que se encuentra con el mejor indicador de espacio público, y 19, la localidad con el peor indicador de espacio público, se resalta que:

- Al analizar las 3 localidades con mayor nivel de pobreza por ingresos (Ciudad Bolívar, Usme y Bosa), estas presentaron, en términos de EPE, los puestos 5, 6 y 10, respectivamente, en cuanto al indicador por área de espacio, y los puestos 14,7 y 18 , respectivamente, si se analiza por habitante. En el caso del EPV, las mismas localidades ocuparon los puestos 5,1 y 6 , respectivamente, en cuanto a dotación por área, y los puestos 9, 1 y 10, respectivamente, por habitante. En términos de EPT, finalmente, ocuparon los puestos 6,4 y 8 , respectivamente, en dotación por área, y los puestos 16, 1 y 17 , respectivamente, por habitante.

- Al hacer el análisis de las 3 localidades con mayor nivel del IPM (Usme, Bosa y Santa Fe), se encontró que, en términos de EPE, dichas localidades ocuparon los puestos 6, 10 y 16, respectivamente, en dotación por área, y los puestos 5, 18 y 2, respectivamente, si se analiza por habitante. En el caso del EPV, ocuparon los puestos 1, 6 y 16 , respectivamente, en dotación por área, y los puestos 1, 10 y 7, respectivamente, por habitante. En términos de EPT, ocuparon los puestos 4,8 y 16 , respectivamente, en dotación por área, y los puestos 1, 17 y 5 , respectivamente, por habitante.

- Así mismo, al analizar las 3 localidades con mayor nivel de pobreza por NBI (Santa Fe Ciudad Bolívar y Rafael Uribe), se evidenció que, en términos de EPE, dichas localidades ocuparon los puestos 16, 5 y 13 , respectivamente, en dotación por área, y los puestos 2, 14 y 13, respectivamente, si se analiza por habitante. En términos de EPV, ocuparon los puestos 16,5 y 15 , respectivamente, en dotación por área, y los puestos 7, 9 y 17, respectivamente, si se analiza por habitante.
En términos de EPT, ocuparon los puestos 16, 6 y 14, respectivamente, en dotación por área, y los puestos 5,16 y 18 , respectivamente, si se analiza por habitante.

En términos generales, se observó que las dotaciones de espacio público no están cumpliendo con los principios de focalización ni con el criterio de equidad, pues dicho principio indicaría que las localidades más pobres deberían presentar mejores indicadores de espacio público, o que, en promedio, todas las localidades deberían presentar indicadores similares por habitante.

Así mismo, es fundamental resaltar que las localidades más pobres bajan de posición en el ranking cuando los indicadores son analizados en términos por habitante, caso contrario al de las localidades con mejores indicadores de pobreza, que, al ser menos densas (figura 6), presentan mayores dotaciones si se analiza por habitante.

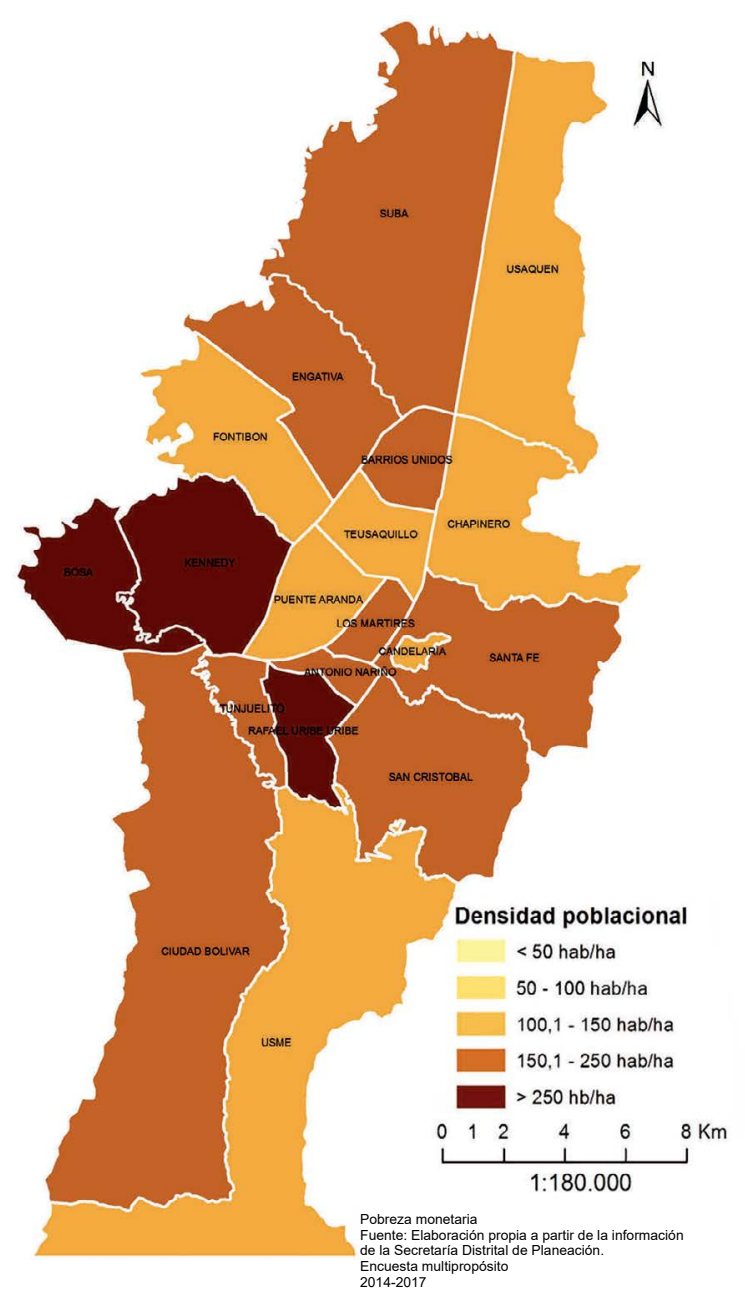

(4igura 6. Densidad poblacional.

Fuente: elaboración propia, con base en información de la Secretaría de Planeación de Bogotá (2017). CC BY-NC

D Tabla 3. Correlaciones $\checkmark$ pobreza y espacio público. Fuente: elaboración propia con información del Observatorio del Espacio Público de Bogotá. (2017) CC BY-NC

(7) Tabla 4. Correlaciones (v) pobreza y espacio público por habitante.

Fuente: elaboración propia, con base en información del Observatorio del Espacio

Público de Bogotá. (2017) CC BY-NC

\begin{tabular}{|c|c|c|c|c|}
\hline Índice & $\begin{array}{c}\text { Pobreza } \\
\text { monetaria }\end{array}$ & $\begin{array}{l}\text { Incidencia, pobreza } \\
\text { multidimensional }\end{array}$ & ICV & $\begin{array}{l}\% \text { de personas } \\
\text { pobres por NBI }\end{array}$ \\
\hline EPE & $-0,178$ & $-0,1187$ & 0,1753 & $-0,2374$ \\
\hline EPV & 0,2181 & 0,2236 & $-0,1629$ & $-0,0015$ \\
\hline EPT & 0,024 & 0,0569 & 0,0163 & $-0,1394$ \\
\hline
\end{tabular}

\begin{tabular}{|c|c|c|c|c|}
\hline Índice & $\begin{array}{c}\text { Pobreza } \\
\text { monetaria }\end{array}$ & $\begin{array}{c}\text { Incidencia, pobreza } \\
\text { multidimensional }\end{array}$ & $\mathrm{ICV}$ & $\begin{array}{l}\% \text { de personas } \\
\text { pobres por } \mathrm{NBI}\end{array}$ \\
\hline EPE m²/hab & $-0,34$ & $-0,45$ & 0,52 & $-0,16$ \\
\hline $\mathrm{EPV} \mathrm{m}^{2} / \mathrm{hab}$ & 0,24 & 0,12 & $-0,04$ & 0,08 \\
\hline $\mathrm{EPTm}^{2} / \mathrm{hab}$ & $-0,15$ & $-0,30$ & 0,38 & $-0,18$ \\
\hline
\end{tabular}


Figura 7. Curva de Lorenz. Fuente: elaboración propia, a partir de Medina (2001).

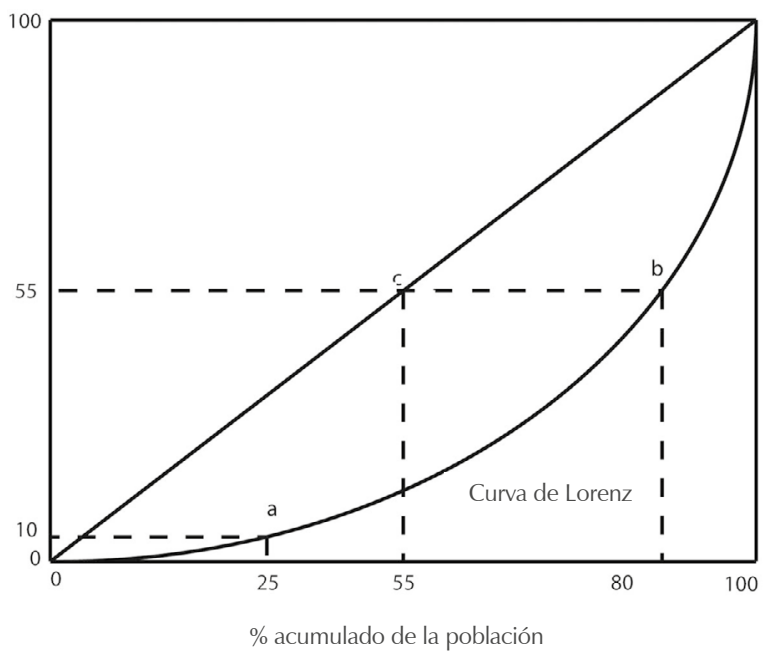

Coeficiente de correlación

Con el fin de analizar con mayor profundidad el comportamiento de la dotación de espacio público en términos de $\mathrm{m}^{2}$ y de $\mathrm{m}^{2} /$ hab respecto a las cifras de pobreza, se estimó el coeficiente de correlación. Este permite analizar la relación lineal entre las dos variables independientemente de las escalas de la medida de las variables.

Si el coeficiente de correlación es cercano a 1, existe una relación positiva, lo cual indicaría que a mayor nivel de pobreza, mayor dotación de espacio público. Por su parte, si el coeficiente de correlación es de cero, no existe relación lineal entre las variables, lo que podría indicar, de manera débil, una "igualdad en la dotación de espacio público". Y si el índice de correlación es negativo, existe una relación inversa entre las variables, lo cual indica que a menor nivel de pobreza, mayor dotación de espacio público, y se podría hablar de "inequidad" en la dotación de espacio público.

Al analizar las correlaciones de las diferentes medidas de pobreza respecto a las dotaciones de espacio público (tabla 3), se encontró que para todos los índices de pobreza el índice de correlación respecto al espacio público efectivo es negativo, excluyendo el caso del índice de condiciones de vida, por cuanto este, a diferencia de los demás, es menor cuando la población es más pobre.

Al hacer nuevamente la correlación, pero ya no respecto al total de $\mathrm{m}^{2}$ de la localidad, sino a los $\mathrm{m}^{2} /$ hab (tabla 4), los índices de correlación fueron mayores en términos absolutos, aspecto que resalta lo que ya se mencionó: en las localidades pobres, al ser más densas, su déficit de espacio público se ve reforzado en términos per cápita. Respecto al indicador de EPV, este presentó resultados más alentadores en términos de focalización, pues presenta una relación débil, pero positiva, aunque muestra la misma tendencia en términos por habitante.

\section{La desigualdad en la distribución del espacio público}

Para evaluar la desigualdad en la distribución del espacio público, se utilizaron diagramas de distribución, que permiten un análisis más detallado de la desigualdad, pues identifican unos aspectos de forma propios de dicha desigualdad que el análisis estadístico no consigue. A partir de 1905, una de las formas más habituales para representar la desigualdad es la curva de Lorenz. En términos prácticos, esta gráfica representa el porcentaje acumulado de la variable (\%Yi) que es percibido o que posee un determinado porcentaje de la población $(\% \mathrm{Pi})$; este es ordenado de forma ascendente, acorde con la cantidad que dicho individuo posea de la variable (Medina, 2001).

La elaboración de la curva de Lorenz se da partiendo de $\mathrm{n}$ individuos ordenados de manera ascendente respecto al valor que estos posean de la variable $Y$. De este ordenamiento se conforman grupos de igual tamaño, llamados percentiles (los grupos más usados son: con el $10 \%$ de la población, que se llaman deciles; con el 20\%, quintiles, y con el $25 \%$, cuartiles). Por tanto, la curva de Lorenz (figura 8) muestra la relación que existe entre los porcentajes de la población y las proporciones acumuladas de la variable (Medina, 2001).

La forma como la curva muestra gráficamente la distribución está dada por la línea de equidad perfecta. Dicha curva, de $45^{\circ}$, se formaría intuitivamente si a cada uno de los individuos le correspondiera el mismo porcentaje de la variable, lo cual denotaría ausencia de desigualdad. Esta línea sirve como referente para delimitar (conforme a la distribución que tenga la variable) lo que se llamará área de concentración, la cual permitirá evidenciar la desigualdad y servirá como base para el cálculo de los diferentes índices.

De igual manera, indagando en la literatura en términos de desigualdad, se encuentra que la medida por excelencia para cuantificar este fenómeno es el denominado coeficiente de concentración de Gini (Medina, 2001). Dicho indicador es usado comúnmente para medir la concentración en los ingresos o en la tenencia de tierras. Por eso, mediante ponderaciones en términos de área, se tratará de medir la concentración de los espacios públicos en determinadas zonas de la ciudad.

En las figuras 9 y 10 se presentan la curva de Lorenz y los coeficientes de desigualdad, y en las tablas 5, 6 y 7, las resultantes para la ciudad de Bogotá, en términos de espacio público efectivo, EPE, espacio público verde, EPV y espacio público total, EPT.

Los anteriores indicadores evidenciaron que para los tres casos (EPE, EPV y EPT), su distribución muestra inequidades bastante altas. Para el caso del EPV, el índice de Gini es de 0,84, lo cual muestra una fuerte acumulación en el último decil. Así mismo, se encontró que las medidas de dispersión de los datos son bastante amplias; dicho fenómeno es explicable, principalmente, por la composición del indicador, pues al estar formado en el $57 \%$ por la Estructura Ecológica Principal se hace muy difícil modificar las condiciones geográficas que generan dicha desigualdad.

Respecto a los indicadores del EPE, se encontró que, si bien las medidas de desigualdad indican 


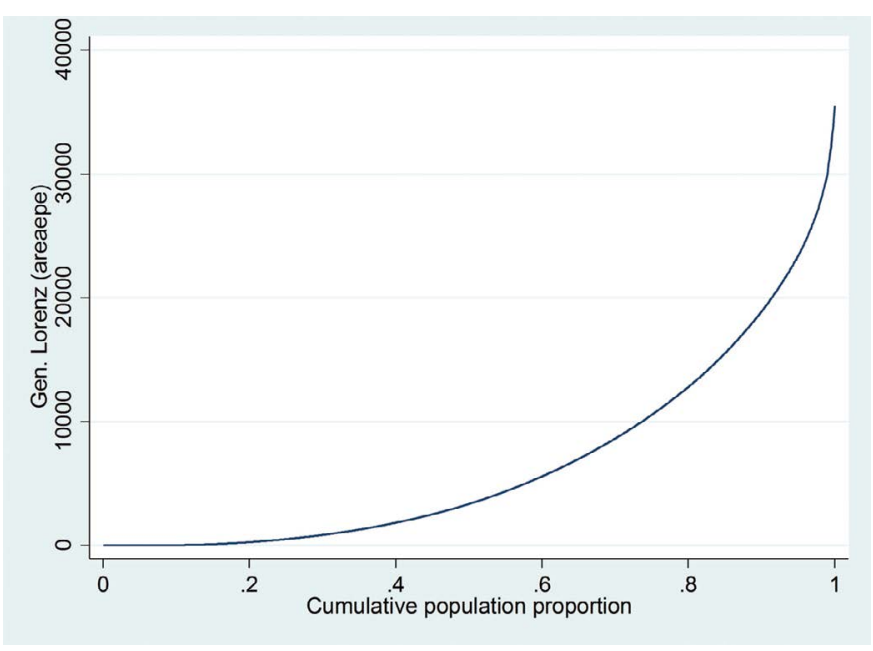

(A) Figura 8. Curva de Lorenz de espacio público efectivo, EPE. Fuente: elaboración propia (2017). CC BY-NC

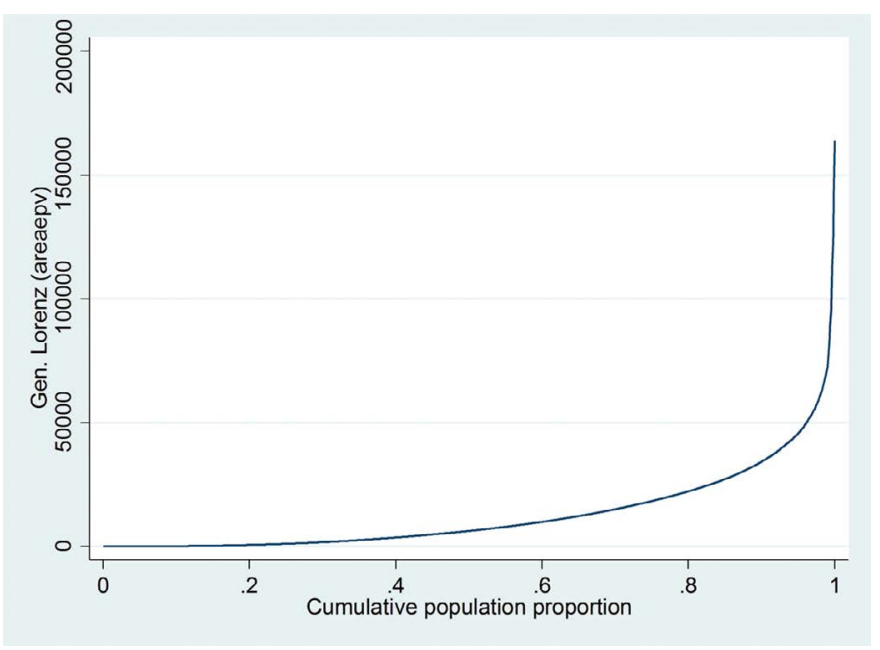

A Figura 9. Curva de Lorenz del espacio público verde, EPV. Fuente: elaboración propia (2017). CC BY-NC

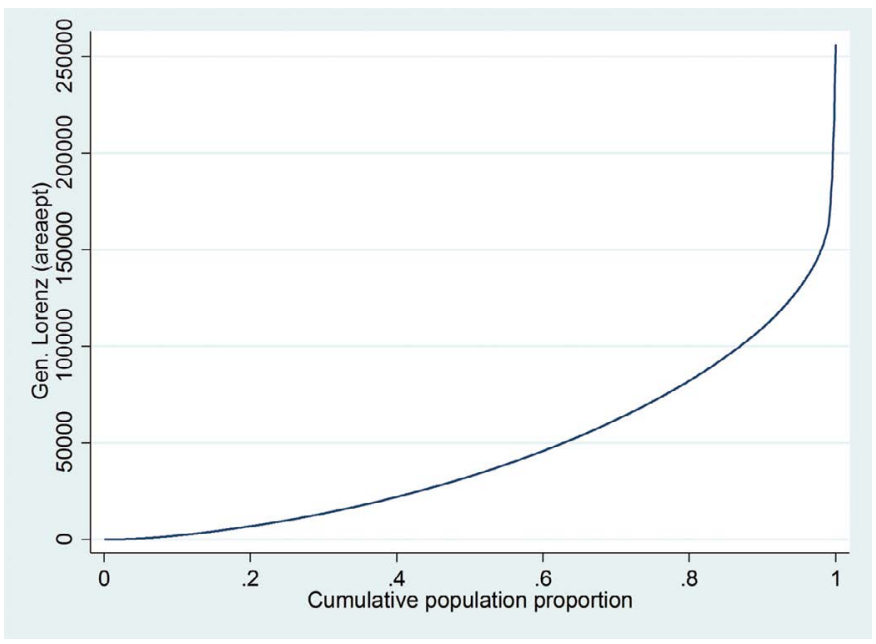

A Figura 10. Curva de Lorenz del espacio público total, EPT.

Fuente: Elaboración propia (2017). CC BY-NC

una alta concentración en la distribución, este es el tipo de espacio público que presenta el menor grado de desigualdad. Es importante entender que, en términos generales, las tipologías que componen dicha categoría son fundamentales para el desarrollo de las personas como ciudadanos (parques, zonas verdes, plazas y plazoletas).

En relación con el EPT, se encontró que, si bien este presenta un coeficiente de Gini más alto que el referente al EPE, al incluir en la distribución el sistema vial, presente en toda la ciudad, la desigualdad, aunque alta, es menor que

\begin{tabular}{|c|c|}
\hline \multicolumn{2}{|l|}{ Desviación media relativa } \\
\hline Coeficiente de variación & 1,8537893 \\
\hline Desviación estándar de los registros & 1,6994243 \\
\hline Coeficiente de Gini & 0,6260355 \\
\hline Índice de desigualdad de Mehran & 0,7788294 \\
\hline Índice de desigualdad de Piesch & 0,5496386 \\
\hline Índice de desigualdad de Kakwani & 0,317407 \\
\hline Índice de entropía de Theil & 0,7923174 \\
\hline Desviación media del índice de Theil & 0,7636223 \\
\hline
\end{tabular}

(A) Tabla 5. Medidas de desigualdad de área de espacio público efectivo, EPE. Fuente: elaboración propia (2017).

\begin{tabular}{|c|c|}
\hline Desviación media relativa & 0,691098 \\
\hline Coeficiente de variación & 6,6188068 \\
\hline Desviación estándar de los registros & 1,7033493 \\
\hline Coeficiente de Gini & 0,8450449 \\
\hline Índice de desigualdad de Mehran & 0,9131407 \\
\hline Índice de desigualdad de Piesch & 0,810997 \\
\hline Índice de desigualdad de Kakwani & 0,5848931 \\
\hline $\begin{array}{l}\text { Índice de entropía de Theil } \\
\text { In }\end{array}$ & $\begin{array}{r}2,4105297 \\
\ldots \ldots \ldots \ldots \ldots \ldots\end{array}$ \\
\hline Desviación media del índice de Theil & 1,6016064 \\
\hline
\end{tabular}

A Tabla 6. Medidas de desigualdad de espacio público verde, EPV. Fuente: elaboración propia (2017).

\begin{tabular}{|c|c|}
\hline Desviación media relativa & 0,4809139 \\
\hline Coeficiente de variación & 4,2916258 \\
\hline Desviación estándar de los registros & 1,1840011 \\
\hline Coeficiente de Gini & 0,6445744 \\
\hline Índice de desigualdad de Mehran & 0,7379593 \\
\hline Índice de desigualdad de Piesch & 0,5978819 \\
\hline Índice de desigualdad de Kakwani & 0,3475154 \\
\hline Índice de entropía de Theil & 1,3438856 \\
\hline Desviación media del índice de Theil & 0,8301252 \\
\hline
\end{tabular}

A Tabla 7. Medidas de desigualdad de espacio público total, EPT. Fuente: elaboración propia (2017) la que se presentaba debido a la Estructura Ecológica Principal. De igual manera, al evidenciar gráficamente la curva de Lorenz, se logró determinar que el sistema vial se encuentra mejor distribuido frente a los otros elementos del espacio público evaluados en el indicador de EPT a lo largo de la ciudad.

\section{Discusión}

El crecimiento urbano de Bogotá ha contribuido al aumento de las desigualdades sociales, por cuanto la dinámica urbanística ha estado formada 
por procesos que han dificultado las dotaciones de espacio público. Aspectos como la ubicación geográfica en la periferia, los desarrollos no legalizados y las lógicas inmobiliarias generan asimetrías en las dotaciones de espacio público, al violar los principios de igualdad y de progresividad que estipula la Constitución.

El estudio, por medio de los análisis realizados y de los mapas, demuestra que en los principales componentes del espacio público de una ciudad (los parques, las plazas y las plazoletas, como lugares de encuentro y como lugares que van a brindar condiciones favorables para aumentar la calidad de la vida de los habitantes) no se encuentran distribuidos de forma equitativa en la ciudad, y al analizar dicho fenómeno a la luz del principio de la focalización, se encuentra que los indicadores más bajos de espacio público se encuentran en las localidades donde los indicadores de pobreza son altos.

A través de este análisis, se buscó determinar si existía equidad en la dotación de espacio público, lo cual se tornó complejo, debido a la heterogeneidad de las localidades (en términos físicos, sociales y económicos), entendiendo estas últimas como las unidades más desagregadas de las que se encontró información relevante sobre pobreza.

Al analizar la correlación entre pobreza y espacio público, se encontró que, en términos generales, estas dos magnitudes eran mayormente débiles y negativas, lo cual indica que a menor nivel de pobreza, mayor dotación de espacio público, lo cual viola la hipótesis planteada de equidad.

Igualmente, al analizar las tres localidades más pobres en términos de ingresos, IPM y NBI, para evaluar qué posición ocupan en un ranking ordenado de mayor a menor, en términos de la dotación de espacio público, se evidenció que estas se encuentran, en su mayoría, en posiciones donde el déficit de espacio público predomina.

Dichos resultados revelan que las dotaciones de espacio público no se encuentran focalizadas, lo cual se torna preocupante, pues prende las alarmas frente a los programas, los proyectos y las inversiones que realiza el gobierno de la ciudad para dotar el espacio urbano con equidad.

Localidades como Ciudad Bolívar, Bosa y Los Mártires cuentan con indicadores de pobreza monetaria de 29,3, 23,5 y 15,6, respectivamente, y de pobreza extrema de $6,3,5,2$ y 4,6, frente a indicadores de espacio público efectivo de 3,2 $\mathrm{m}^{2} / \mathrm{hab}$, de $2,1 \mathrm{~m}^{2} /$ hab y de $2,0 \mathrm{~m}^{2} /$ hab, respectivamente. Siguiendo el principio de focalización, estas localidades deberían contar con indicadores similares a los de localidades que presentan mejores condiciones de pobreza, como la de Chapinero, que cuenta con indicadores de espacio público efectivo de $8,2 \mathrm{~m}^{2} / \mathrm{hab}$, o la de Barrios Unidos, con 6,6 $\mathrm{m}^{2} / \mathrm{hab}$.

Las anteriores mediciones implican un reto importante para modificar las condiciones en las cua- les se generan espacios públicos. Aunque dicha dinámica es tendencia en América Latina, en países como Colombia y en ciudades como Bogotá, donde la desigualdad de ingresos es tan notoria, se hace necesario tomar cartas en el asunto generando mecanismos para la creación de nuevos espacios, ya sea mediante una destinación de gasto que cumpla el principio de la focalización o creando mecanismos de transferencia de las zonas de cesión de zonas que se encuentran bien dotadas a las zonas más deficitarias de espacio público.

El gobierno debe, entonces, generar políticas contundentes, que garanticen la construcción de más espacio público en la ciudad, bajo el principio de la focalización, que no solo van a aumentar los niveles de calidad de vida de todos sus habitantes, sino que va a poner en marcha políticas de largo plazo que van a hacerlo posible cumpliendo con los postulados expuestos por Sen (2002) sobre la igualdad basal, de acuerdo con las creencias de nuestra sociedad, buscando una igual posibilidad de acceso y disfrute de los servicios sociales (dotaciones), y no una igual cantidad de servicios (Matallana, 2010).

Los hallazgos del estudio son consistentes con estudios realizados por la CEPAL (2010) en otras ciudades de América Latina, sobre calidad de vida y acceso a servicios públicos, en una región donde, debido a los procesos de urbanización informal, no se toman en cuenta los espacios públicos como elementos esenciales para el desarrollo urbano y la calidad de vida de los ciudadanos, lo que genera grandes brechas frente a zonas de la ciudad urbanizados de manera formal y los desarrollos informales. De igual manera, con el presente estudio se puede concluir que el espacio público en las zonas de mayor pobreza no representa una inversión para los promotores urbanos (sean formales o informales), mientras que para niveles de ingresos altos puede llegar a ser un plusvalor.

Para estudios realizados por Mayorga y García (2018), la proximidad física de los espacios de ocio cobra importancia en los contextos de expansión de la ciudad funcional, donde se deben recorrer grandes distancias para el desarrollo de actividades laborales, al igual que, en algunos contextos, para el acceso a servicios de salud, recreación y deporte. La equidad, entonces, tiene injerencia y juega un papel decisivo al momento de analizar la proximidad física, la cantidad y la accesibilidad de los espacios.

De esta forma, el presente estudio da la pauta para realizar otras investigaciones donde se pueda relacionar otras variables, además de la pobreza, frente a la equidad en la distribución de los espacios públicos en la ciudad, como las rentas generadas por la cercanía a un parque o una zona verde, o bien, estudios de origen-destino frente al acceso de actividades recreativas-deportivas. 


\section{Conclusiones}

El presente estudio permite evidenciar la necesidad de vincular, y de manera contundente, en las agendas de las políticas de la planificación de la ciudad el principio de la focalización, con el fin de garantizar el acceso a los espacios públicos a todos los habitantes de la ciudad, sin importar su nivel de ingreso, su estrato socioeconómico o su localización en la ciudad.

El ejercicio realizado por medio de la correlación y la curva de Lorenz permitió evidenciar las inequidades presentes en Bogotá respecto a la distribución del espacio público en relación con los niveles de pobreza en las diferentes localidades.

Estos resultados llevan a confirmar que la producción de espacio público ha sido mayor en las localidades donde priman las lógicas inmobiliarias de carácter privado, respondiendo a la norma impuesta por la ciudad, y que cuentan con los menores niveles de pobreza de la ciudad, lo cual genera una ciudad con condiciones de inequidad en el acceso al espacio público.

Este tipo de análisis en torno al espacio públiCo, a la calidad de vida y a los diferentes niveles de pobreza en la ciudad resulta de interés, al evidenciar que las relaciones y las condiciones territoriales entran a jugar un papel de importancia en el bienestar de los ciudadanos, y que se han convertido en un eje de estudio importante para distintas disciplinas al realizar estudios transdisciplinares.

Para futuras investigaciones, son necesarios análisis a una escala más detallada, debido a las particularidades que presentan las localidades de la ciudad en su interior, en todos los aspectos (sociales, económicos, ambientales). Con la nueva producción de instrumentos y la democratización de la información por medio de plataformas de libre acceso, se pueden desarrollar análisis con más detalle para la ciudad, que permitan focalizar de una mejor forma las inversiones y conocer la dinámica urbana de forma más cercana.

\section{Referencias}

Borja, J. (2003). La ciudad conquistada. Madrid: Alianza.

Borja, J., \& Muxi, Z. (2001). El espacio público: ciudad y ciudadanía. Barcelona: Sociedad Editorial Electa España, S. A.

Carrión, F. (2004). Espacio público: punto de partida para la alteridad. Fabio Velásquez Carrollo. (comp.) Ciudad e inclusión: Por el derecho a la ciudad (pp. 55-79). Bogotá: Fundación Foro Nacional por Colombia. Fedevivienda. Corporación región.Recuperado de:

https://works.bepress.com/fernando carrion/110/

Castell, M. (2003 abril). Ciudades y urbanismo en la sociedad en red. Segunda jornada de la 5 Bienal de ciudades y urbanistas europeos, Barcelona: Generalitat de Cataluña y el Ayuntamiento de Barcelona.

CEPAL (2010). La hora de la igualdad: Brechas por cerrar, caminos por abrir. Brasilia: Naciones Unidas. Recuperado de: https://repositorio.cepal.org/bitstream/ handle/11362/13309/S2010986_es.pdf

Davis, M. (2001). Control Urbano: la ecología del miedo. Barcelona: La Llevir Virus Editorial.

Departamento Administrativo de Espacio Público (DADEP) (2017). Reporte técnico de indicadores de espacio público 2017. Bogotá: Alcaldía Mayor de Bogotá. Recuperado de: http://observatorio.dadep.gov.co/sites/default/ files/2018/Reporte-tecnico-2-2017.pdf

Departamento Nacional de Estadística (DANE). (2014). Metodología índice de pobreza multidimensional (IPM), Dirección Técnica de Metodología y Producción Estadística (DIMPE).

Recuperado de: http://microdatos.dane.gov. co/index.php/catalog/330/related_materials

Habermas, J. (1993). The structural transformation of the public sphere. An inquiry into category of a bourgeois society. Cambridge, Massachusetts: MIT Press. Recuperado de http://courses.ischool.berkeley.edu/i218/ s15/Habermas_STBPS_I.Intro.pdf
Kirby, A. (1983), Neglected factors in public services research: A Comment on 'Urban Structure and Geographical Access to Public Services. Annals of the Association of American Geographers, 73(2), 285-295.

Ley 1176 de 2007. Por la cual se desarrollan los artículos 356 y 357 de la Constitución Política y se dictan otras disposiciones. (27 de diciembre de 2007). DO 46.854. Recuperado de: https://www.funcionpublica.gov.co/eva/ gestornormativo/norma.php?i=28306

Ley 715 de 2001. Por la cual se dictan normas orgánicas en materia de recursos y competencias de conformidad con los artículos 151, 288, 356 y 357 (Acto Legislativo 01 de 2001) de la Constitución Política y se dictan otras disposiciones para organizar la prestación de los servicios de educación y salud, entre otros. (21 de diciembre de 2001). DO 44654. Recuperado de: http://www.secretariasenado.gov.co/senado/ basedoc/ley 0715 2001.html

Matallana, J. (2010). Equidad espacial en el acceso a la educación inicial en Bogotá. Bogotá: Universidad de los Andes. Centro Interdisciplinario de Estudios sobre Desarrollo.

Mayorga Henao, J., \& García, D. (2018). Calidad de vida y acceso inequitativo al espacio público en Bogotá. Documents D'AnàLisi GeogràFica, 65(1), 69-92. https://doi.org/10.5565/rev/dag.436

Medina, F. (2001). Consideraciones sobre el índice de Gini para medir la concentración del ingreso. Serie estudios estadísticos y prospectivos. Santiago de Chile. CEPAL. Recuperado de: https://repositorio.cepal.org/handle/11362/4788

Morales R. (2000). Métodos para medir la pobreza. La Paz: Universidad Andina Simón Bolívar. Recuperado de:

http://www.ciess-econometrica.com. bo/index.php/publicaciones/libros/13metodos-para-medir-la-pobreza

Naciones Unidas. (2014). La situación demográfica en el mundo. Informe conciso. Serie Asuntos económicos y sociales. New York: Naciones Unidas. Recuperado de

https://www.un.org/en/development/desa/ population/publications/pdf/trends/Concise $\% 20$ Report\%20on\%20the\% 20World\%20 Population\%20Situation\%202014/es.pdf
Naciones Unidas. (2016). Informe de los objetivos de desarrollo sostenible 2016. New York: Naciones Unidas. Recuperado de:: https://unstats.un.org/sdgs/report/2016/ the $\% 20$ sustainable\%20development $\% 20$ goals\%20report\%202016_spanish.pdf

Rawls, J. (1971). Teoría de la Justicia. México: Fondo de Cultura Económica.

Secretaría Distrital de Planeación SDP. (2015). Encuesta Multipropósito 2014: principales resultados en Bogotá y la Región. Boletín 70. Serie Bogotá Ciudad de Estadísticas. Bogotá. Recuperado de:

http://www.sdp.gov.co/sites/default/files/boletin resultados encuesta multiproposito 2014.pdf

Secretaría Distrital de Planeación (SDP). (2017). Encuesta Multipropósito 2017. Bogotá.Recuperado de::

http://www.sdp.gov.co/gestionestudios-estrategicos/estudios-macro/ encuesta-multiproposito/encuestamultiproposito-2017

Segovia, O., Jordán, R. (2005). Espacios públicos urbanos, pobreza y construcción social. Serie Medio Ambiente y Desarrollo 122. 52p. Santiago de Chile: CEPAL.

Sen, A. (2002). Economía de bienestar y dos aproximaciones a los derechos. Bogotá: Universidad Externado de Colombia, Facultad de Derecho. 


\section{Vol.}
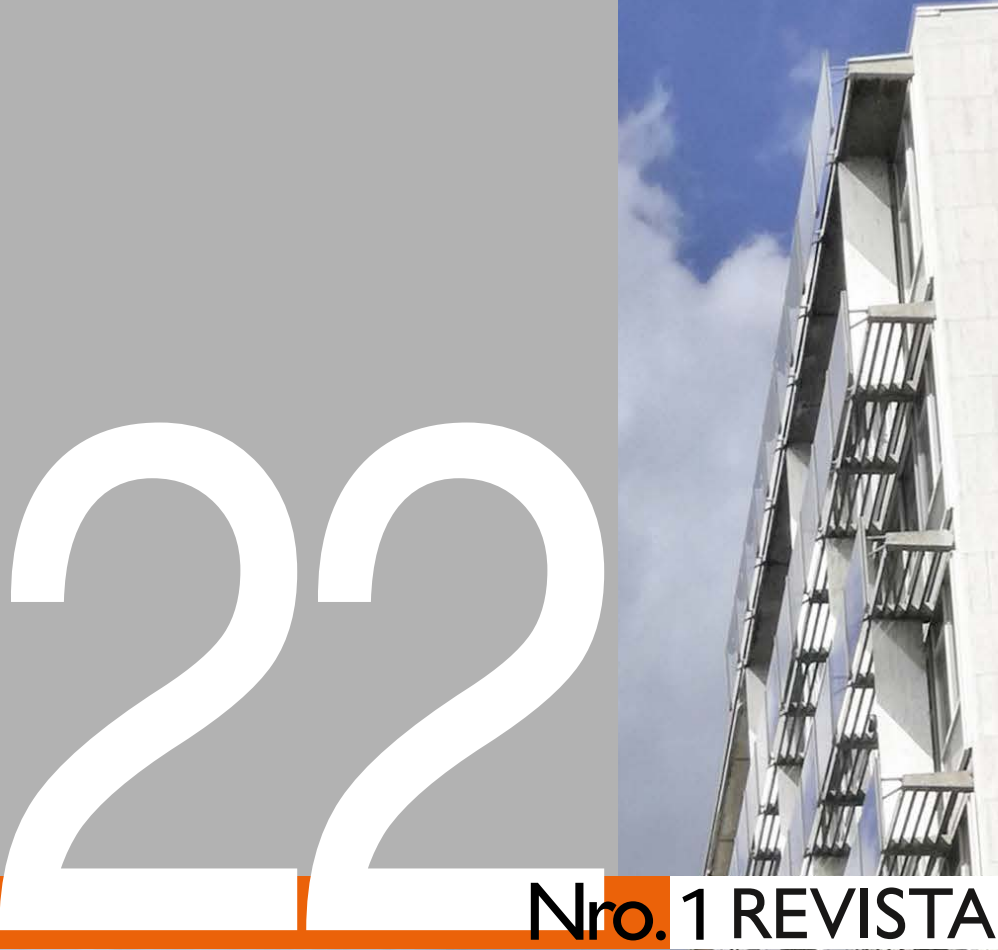

ISSN: 1657-0308 (Impresa)

Nro. 1 REVISTA DE ARQUITECTURA

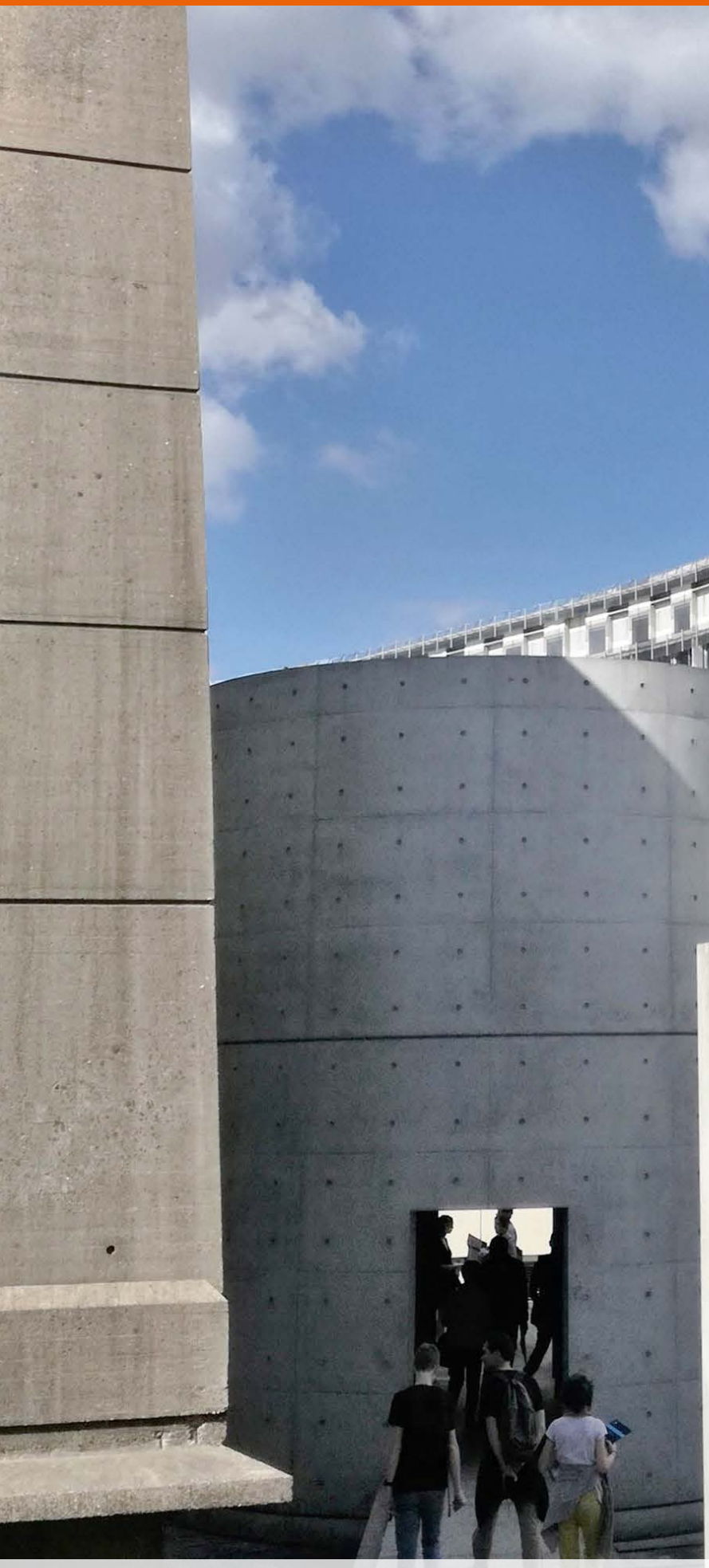

$\overline{9}$
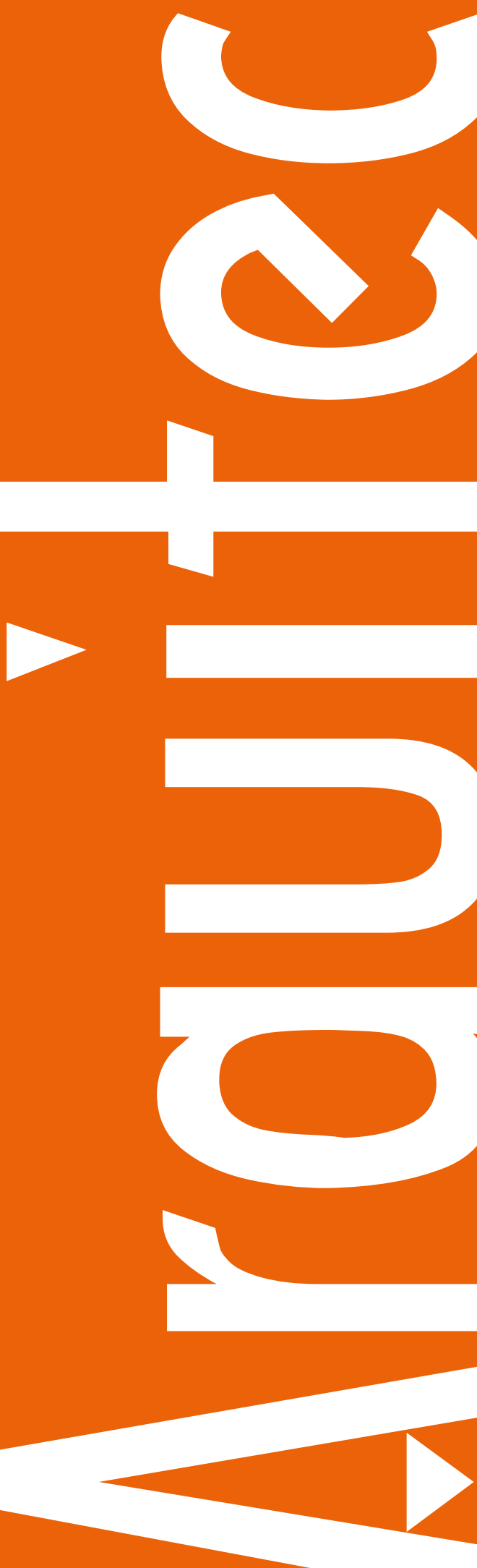


\section{Enfoque y alcance}

La Revista de Arquitectura (Bogotá) ( (ISSN 1657-0308 Impresa y E-ISSN 2357-626X en línea) es una publicación científica seriada de acceso abierto, arbitrada mediante revisión por pares (doble ciego) e indexada, en donde se publican resultados de investigación originales e inéditos.

Está dirigida a la comunidad académica y profesional de las áreas afines a la disciplina. Es editada por la Facultad de Diseño y el Centro de Investigaciones (CIFAR) de la Universidad Católica de Colombia en Bogotá (Colombia).

La principal área científica a la que se adscribe la Revisto de Arquitectura (Bogotá) según la OCDE es:

Gran área: 6. Humanidades

Área: 6.D. Arte

Disciplina: 6D07. Arquitectura y Urbanismo

También se publican artículos de las disciplinas como 2A02, Ingeniería arquitectónica; 5C03, Estudios urbanos (planificación y desarrollo); 6D07, Diseño.

Los objetivos de la Revista de Arquitectura (Bogotá) son:

- Promover la divulgación y difusión del conocimiento generado a nivel local, nacional e internacional

- Conformar un espacio para la construcción de comunidades académicas y la discusión en torno a las secciones definidas.

- Fomentar la diversidad institucional y geográfica de los autores que participan en la publicación.

- Potenciar la discusión de experiencias e intercambios científicos entre investigadores y profesionales.

- Contribuir a la visión integral de la arquitectura, por medio de la concurrencia y articulación de las secciones mediante la publicación de artículos de calidad.

- Publicar artículos originales e inéditos que han pasado por revisión de pares, para asegurar que se cumplen las normas éticas, de calidad, validez científica, editorial e investigativa.

- Fomentar la divulgación de las investigaciones y actividades desarrolladas en la Universidad Católica de Colombia.
Palabras clave de la Revista de Arquitectura (Bogotá): arquitectura, diseño, educación arquitectónica, proyecto y construcción, urbanismo.

Idiomas de publicación: español, inglés, portugués y francés. Título abreviado: Rev. Arquit.

\section{Titulo corto: RevArq}

\section{Políticas de sección}

La revista se estructura en tres secciones correspondientes a las líneas de investigación activas y aprobadas por la institución, y dos complementarias, que presentan dinámicas propias de la Facultad de Diseño y las publicaciones relacionadas con la disciplina.

Cultura y espacio urbano. En esta sección se publican los artículos que se refieren a fenómenos sociales en relación con el espacio urbano, atendiendo aspectos de la historia, el patrimonio cultural y físico, y la estructura formal de las ciudades y el territorio.

Proyecto arquitectónico y urbano. En esta sección se presentan artículos sobre el concepto de proyecto, entendido como elemento que define y orienta las condiciones proyectuales que devienen en los hechos arquitectónicos o urbanos, y la forma como estos se convierten en un proceso de investigación y nuevo de conocimiento. También se presentan proyectos que sean resultados de investigación, los cuales se validan por medio de la ejecución y transformación en obra construida del proceso investigativo. También se contempla la publicación de investigaciones relacionadas con la pedagogía y didáctica de la arquitectura, el urbanismo y el diseño.

Tecnología, medioambiente y sostenibilidad. En esta sección se presentan artículos acerca de sistemas estructurales, materiales y procesos constructivos, medioambiente y gestión, relacionados con los entornos social-cultural, ecológico y económico.

Desde la Facultad. En esta sección se publican artículos generados en la Facultad de Diseño, relacionados con las actividades de docencia, extensión, formación en investigación o internacionalización, las cuales son reflejo de la dinámica y de las actividades realizadas por docentes, estudiantes y egresados; esta sección no puede superar el $20 \%$ del contenido.

Textos. En esta sección se publican reseñas, traducciones y memorias de eventos relacionados con las publicaciones en Arquitectura y Urbanismo.
A Frecuencia de publicación

Desde 1999 y hasta el 2015, la Revista de Arquitectura (Bogotá) publicó un volumen al año, a partir del 2016 se publicarán dos números por año en periodo anticipado, enero-junio y julio-diciembre, pero también maneja la publicación anticipada en línea de los artículos aceptados (versión Post-print del autor).

La Revista de Arquitectura (Bogotá) se divulga mediante versiones digitales (PDF, HTML, EPUB, XML) e impresascon un tiraje de 700 ejemplares, los tiempos de producción de estas versiones dependerán de los cronogramas establecidos por la editorial.

Los tiempos de recepción-revisión-aceptación pueden tardar entre seis y doce meses dependiendo del flujo editorial de cada sección y del proceso de revisión y edición adelantado.

Con el usuario y contraseña asignados, los autores pueden ingresar a la plataforma de gestión editorial y verificar el estado de revisión, edición o publicación del artículo.

\section{A Canje}

La Revista de Arquitectura (Bogotá) está interesada en establecer canje con publicaciones académicas, profesionales o científicas del área de Arquitectura y Urbanismo, como medio de reconocimiento y discusión de la producción científica en el campo de acción de la publicación.

\section{Mecanismo}

Para establecer canje por favor descargar, diligenciar y enviar el formato: RevArq FP20 Canjes
Universidad Católica de Colombia (2020, enero-junio). Revista de Arquitectura (Bogotá), 22(I) I-188. Doi: 10.14718

ISSN: 1657-0308 E-ISSN: 2357-626X

Especificaciones:

Formato: $34 \times 24 \mathrm{~cm}$

Papel: Mate $115 \mathrm{~g}$

Tintas: Negro y policromía
A Contacto

Dirección postal:

Avenida Caracas No. 46-72.

Universidad Católica de Colombia

Bogotá D.C.(Colombia)

Código postal: 111311

Facultad de Diseño Centro de Investigaciones (CIFAR). Sede El Claustro. Bloque " $\mathrm{L}$ ", 4 piso Diag. 46A No. $15 \mathrm{~b}-10$ Editor, Arq. César Eligio-Triana

Teléfonos:

+57 (1) $3277300-3277333$

Ext. 3109; 3112 o 5146

Fax: +57 (1) 2858895
Correo electrónico: revistadearquitectura@ucatolica.edu.co cifar@ucatolica.edu.co

Página WEB: www.ucatolica.edu.co vínculo Revistas científicas

http://publicaciones.ucatolica.edu.co revistas-cientificas http://editorial.ucatolica.edu.co/ojsucatolica/revistas ucatolica/index.php/RevArq 
